\title{
Crystallization kinetics of nanocrystalline materials by combined X-ray diffraction and differential scanning calorimetry experiments
}

Eva Gil-González ${ }^{\mathrm{a}}$, Antonio Perejón ${ }^{\mathrm{a}, \mathrm{b}, *}$, Pedro E. Sánchez-Jiménez ${ }^{\mathrm{a}}$, Santiago Medina-Carrasco ${ }^{\mathrm{c}}$, Jaroslav Kupčík ${ }^{\mathrm{d}}$, Jan Šubrt ${ }^{\mathrm{d}}$, José Manuel Criado ${ }^{\mathrm{a}}$, Luis A. Pérez-Maqueda ${ }^{\mathrm{a}, *}$

${ }^{a}$ Instituto de Ciencia de Materiales de Sevilla (C.S.I.C.-Universidad de Sevilla). C. Américo Vespucio 49, Sevilla 41092. Spain

${ }^{b}$ Departamento de Química Inorgánica, Facultad de Química, Universidad de Sevilla, Sevilla 41071, Spain

${ }^{c} X$-Ray Laboratory (CITIUS), University of Seville, Avenida Reina Mercedes, 4B., 41012 Sevilla, Spain

${ }^{d}$ Institute of Inorganic Chemistry of the CAS, v.v.i., CZ-250 68 Husinec- ̌̌ež, Czech Republic

\begin{abstract}
Crystallization is one key aspect in the resulting properties of nanocrystalline functional materials and much effort has been devoted to understanding the physical mechanisms involved in these processes as a function of temperature. The main problems associated to crystallization kinetic studies come from the limitations of the employed techniques, and the obtained results may vary significantly depending on the choice of the measurement method. In this work, a complete description of the thermal crystallization event of nanocrystalline $\mathrm{BiFeO}_{3}$ has been performed by combining the information obtained from three different experimental techniques: in situ hightemperature X-ray diffraction, transmission electron microscopy and differential scanning calorimetry. Interestingly, the kinetic analysis of the X-ray diffraction and DSC data yields almost identical results, although the physical properties measured by both techniques are different. This allows the unambiguous determination of the kinetic parameters. The importance of a proper definition of the conversion degree, which is limited by the employed measurement technique, is also highlighted.
\end{abstract}

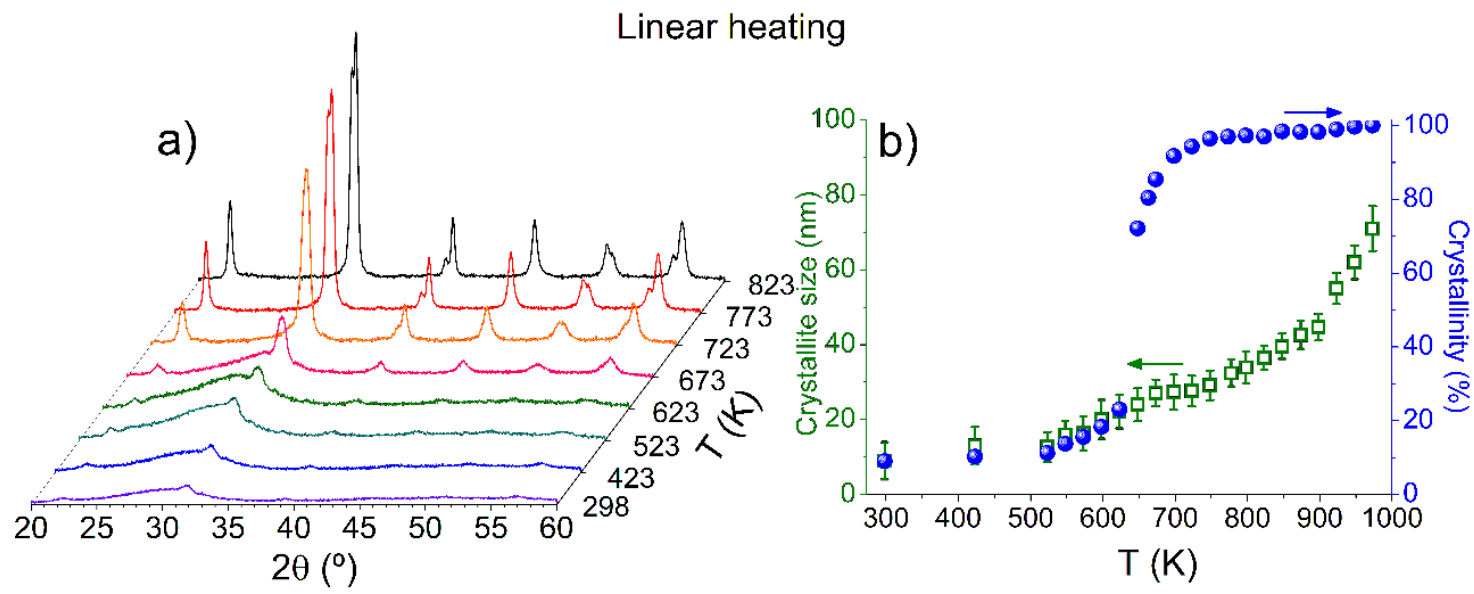

*Corresponding authors:

antonio.perejon@icmse.csic.es

Instituto de Ciencia de Materiales de Sevilla (C.S.I.C.-Univ. Sevilla).

C. Américo Vespucio 49, Sevilla 41092. Spain

Tel. (+34) 954489500

maqueda@cica.es

Instituto de Ciencia de Materiales de Sevilla (C.S.I.C.-Univ. Sevilla).

C. Américo Vespucio 49, Sevilla 41092. Spain

Tel. (+34) 954489548 


\title{
Crystallization kinetics of nanocrystalline materials by combined X-ray diffraction and differential scanning calorimetry experiments
}

Eva Gil-González ${ }^{\mathrm{a}}$, Antonio Perejón ${ }^{\mathrm{a}, \mathrm{b}, *}$, Pedro E. Sánchez-Jiménez ${ }^{\mathrm{a}}$, Santiago MedinaCarrasco $^{\mathrm{c}}$, Jaroslav Kupčík ${ }^{\mathrm{d}}$, Jan Šubrt ${ }^{\mathrm{d}}$, José Manuel Criado ${ }^{\mathrm{a}}$, Luis A. Pérez-Maqueda ${ }^{\mathrm{a}, *}$

${ }^{a}$ Instituto de Ciencia de Materiales de Sevilla (C.S.I.C.-Universidad de Sevilla). C. Américo Vespucio 49, Sevilla 41092. Spain

${ }^{b}$ Departamento de Química Inorgánica, Facultad de Química, Universidad de Sevilla, Sevilla 41071, Spain

${ }^{c} X$-Ray Laboratory (CITIUS), University of Seville, Avenida Reina Mercedes, 4B., 41012 Sevilla, Spain

${ }^{\mathrm{d}}$ Institute of Inorganic Chemistry of the CAS, v.v.i., CZ-250 68 Husinec-̌̌Rez, Czech Republic

*Corresponding authors: antonio.perejon@icmse.csic.es; maqueda@,cica.es

\begin{abstract}
Crystallization is one key aspect in the resulting properties of nanocrystalline functional materials and much effort has been devoted to understanding the physical mechanisms involved in these processes as a function of temperature. The main problems associated to crystallization kinetic studies come from the limitations of the employed techniques, and the obtained results may vary significantly depending on the choice of the measurement method. In this work, a complete description of the thermal crystallization event of nanocrystalline $\mathrm{BiFeO}_{3}$ has been performed by combining the information obtained from three different experimental techniques: in situ high-temperature X-ray diffraction, transmission electron microscopy and differential scanning calorimetry. Interestingly, the kinetic analysis of the X-ray diffraction and DSC data yields almost identical results, although the physical properties measured by both techniques are different. This allows the unambiguous determination of the kinetic parameters. The importance of a proper definition of the conversion degree, which is limited by the employed measurement technique, is also highlighted.
\end{abstract}




\section{Introduction}

There is a recent growing interest in crystallization, as it is involved in many natural and manmade processes. Thus, for example, it has been recently shown that bones are formed by crystallization of amorphous transient phases. ${ }^{1}$ Moreover, it has been demonstrated that some metastable compounds, such as balcite that is a metastable barium substituted calcite, can only be prepared by crystallization from an amorphous precursor. ${ }^{2-3}$ The kinetics of thermal crystallization of nanocrystalline (or amorphous) solids is commonly studied by Xray diffraction (XRD) methods, ${ }^{4-8}$ thermal analysis methods such as differential scanning calorimetry (DSC) and differential thermal analysis (DTA), ${ }^{9-14}$ electrical resistance measurements, ${ }^{15}$ rheology, ${ }^{16}$ and microscopic techniques. ${ }^{4,}$ 14, 17-20 These methods have been applied to crystallization studies of different kind of materials, mainly polymers and polymer nanocomposites, ${ }^{13,21-27}$ metallic systems, ${ }^{28-30}$ chalcogenide glasses ${ }^{7,31-34}$ and metal oxide glasses, ${ }^{35-36}$ among others.

High temperature-XRD and DSC are macroscopic methods that provide in situ but indirect measurements of the crystallinity of the samples as a function of temperature and time. For XRD measurements, the crystallinity could be obtained from the intensity of diffraction peaks. Moreover, Rietveld refinement, which is commonly used, yields information on crystallinity and crystal structure. ${ }^{5,35,37-38}$ Data from high temperature-XRD are typically obtained under stepwise heating or isothermal conditions as recording each individual XRD pattern usually requires certain amount of time, ${ }^{5,8}$ and crystallization progresses even while the pattern is recorded. DSC measures the heat flow released from the sample during the crystallization process. Thus, crystallinity is indirectly monitored by quantifying the area under the DSC peak, but direct information regarding the structural changes undergone by the sample is not provided. DSC is flexible in terms of heating schedule and experiments could be recorded under any heating conditions including conventional isothermal and linear heating rate, ${ }^{21,39-40}$ or more complicated heating profiles such as modulated $^{41-42}$ or sample-controlled temperature changes. ${ }^{43}$ Moreover, experimental conditions should be carefully selected to avoid thermal inertia and heat transfer phenomena. ${ }^{44-46}$ Optical, electron or atomic force microscopies give a direct observation of the samples microstructure, providing very valuable qualitative information. ${ }^{14,}{ }^{17}$ However, obtaining quantitative data is time consuming and challenging as only small sections of the samples could be observed. Recent advances in in situ electron microscopy measurements 
are very promising and interesting but so far they are not extensively used by the scientific community. ${ }^{18-19}$

In this work, it is shown that to achieve a proper description of the kinetics of the crystallization event it is required to combine data obtained from different experimental techniques, such as high temperature-XRD, transmission electron microscopy and differential scanning calorimetry, as each individual technique only provide partial information of the overall process. The material employed for this crystallization study is nanocrystalline $\mathrm{BiFeO}_{3}$. This widely studied multiferroic is a potential candidate to be used in different practical applications such as multistate memory devices, magnetoelectric sensors and spintronics. ${ }^{47-48}$ Crystallization is one key aspect in the resulting properties of this functional material and, for this reason, a great deal of effort should be put in the understanding and development of solid knowledge of the crystallization mechanism and behaviour as a function of temperature.

\section{Experimental}

\subsection{Sample preparation}

Nanocrystalline $\mathrm{BiFeO}_{3}$ was synthesized by mechanical milling from stoichiometric amounts of $\mathrm{Bi}_{2} \mathrm{O}_{3}$ (Sigma-Aldrich 223891-500G, $10 \mu \mathrm{m}, 99.9 \%$ purity) and $\mathrm{Fe}_{2} \mathrm{O}_{3}$ (SigmaAldrich $310050-500 \mathrm{G},<5 \mu \mathrm{m}, \geq 99 \%$ purity) in a planetary mill under 7 bars of oxygen to avoid bismuth reduction. ${ }^{49}$

\subsection{Sample characterization}

Raman spectrum of the nanocrystallite $\mathrm{BiFeO}_{3}$ powders was collected with a dispersive Horiba Jobin Yvon LabRam HR800 microscope with a $20 \mathrm{~mW}$ green laser (532.14 $\mathrm{nm}$ ) and using a 100x objective with a confocal pinhole of $10 \mu \mathrm{m}$. X-ray powder diffraction patterns were collected using a Rigaku Miniflex diffractometer $\left(\mathrm{CuK}_{\alpha}\right.$ radiation, $\lambda=$ $0.15405 \mathrm{~nm}$ ) working at $45 \mathrm{kV}$ and $40 \mathrm{~mA}$. Temperature dependent X-ray powder diffraction patterns were recorded in a Bruker D8 Advance diffractometer equipped with an Anton Paar XRK 900 high temperature chamber, a Bruker Vantec 1 position-sensitive detector with radial Soller slits, and Göbel mirrors (Bruker, Germany) with parallel Johansson geometry in the incident beam for $\mathrm{CuK}_{\alpha}$ radiation. The diffractometer was 
calibrated mechanically according to the manufacturer specifications, while Corundum, $\mathrm{LaB}_{6}$, and silicon, $\mathrm{Si}$, standards were used to check the resolution in a wide range of angles. Measurements were taken within a $2 \theta$ range from $20^{\circ}$ to $60^{\circ}$, a step of $0.022^{\circ}$, time per step of $0.2 \mathrm{~s}$ and tube conditions of $40 \mathrm{kV}$ and $40 \mathrm{~mA}$. The experiments were performed under isothermal conditions at $653 \mathrm{~K}, 663 \mathrm{~K}$ and $673 \mathrm{~K}$, and under linear heating rate $(\beta)$ conditions at $10 \mathrm{~K} \mathrm{~min}^{-1}$ from $303 \mathrm{~K}$ to $1023 \mathrm{~K}$. During the experiments, a continuous flow of $\mathrm{N}_{2}$ through the sample was used by means of a GM50A MKS mass flow controller calibrated for $\mathrm{N}_{2}$ as received, in gas flow rate fixed to $100 \mathrm{~cm}^{3} \mathrm{~min}^{-1}$ in all the tests. The quantification of the percentage of crystalline material was performed by Rietveld refinement,${ }^{50}$ previously eliminating the fluorescence signal from the sample. Le Bail ${ }^{51}$ fits of the patterns allowed calculating coherent crystal lengths (crystallite size) with the software TOPAS 5 (Bruker). ${ }^{52}$ The values of the goodness of fit (GOF) of the adjustment were checked to obtain values close to the unit, and at the same time values of residual factors $\left(\mathrm{R}_{\mathrm{wp}}\right.$ and $\left.\mathrm{R}_{\text {Bragg }}\right)$ were obtained, as small as possible, reaching coherent values. ${ }^{50}$ High resolution transmission electron microscopy (HR-TEM) measurements were carried out using a $300 \mathrm{kV}$ JEOL JEM 3010 UHR electron microscope with a LaB6 electron source and equipped with a Semi STEM. The samples for electron microscopy were prepared by dispersing the $\mathrm{BiFeO}_{3}$ powder in isopropanol for 1 hour, picking up a drop of the diluted supernatant and the subsequent deposition in a glass sample holder. Immediately, the carbon coated grid was smoothly rubbed in the deposited drops and finally the grids were dried slowly at room temperature for the solvent evaporation. Differential scanning calorimetry (DSC) measurements were recorded from $323 \mathrm{~K}$ to 773 K using a DSC Instrument (Q200, TA Instruments) in standard encapsulated aluminium pans and under a nitrogen flow rate of $100 \mathrm{~cm}^{3} \mathrm{~min}^{-1}$. Typical sample size was $20 \mathrm{mg}$. The experiments were carried out at five different $\beta: 2.5 \mathrm{~K} \mathrm{~min}^{-1}, 5 \mathrm{~K} \mathrm{~min}^{-1}, 7.5 \mathrm{~K} \mathrm{~min}^{-1}, 10 \mathrm{~K}$ $\min ^{-1}, 12.5 \mathrm{~K} \mathrm{~min}^{-1}$.

\section{Results and discussion}

\subsection{Crystallization and crystal growth of nanocrystalline $\mathrm{BiFeO}_{3}$}

The mechanosynthesized naonocrystalline $\mathrm{BiFeO}_{3}$ powders were initially characterized by means of X-Ray diffraction and Raman spectroscopy. Figure 1a shows the XRD pattern of the sample. Several low intensity and broad peaks, characteristic of a nanocrystalline 
material, can be observed at $22.4^{\circ}, 31.8^{\circ}, 39.4^{\circ}, 45.8^{\circ}, 51.5^{\circ}$ and $56.9^{\circ}$ that are attributed to the main peaks of the rhombohedral $\mathrm{R} 3 \mathrm{c}$ structure of $\mathrm{BiFeO}_{3}{ }^{53-55}$ The amount of crystalline material of the sample, calculated by means of the Rietveld refinement, was $9 \%$ and the average crystallite size, as determined by the Le Bail fits, was $9 \mathrm{~nm}$. The starting nanocrystalline powders were also characterized by Raman spectroscopy. The Raman spectrum (Figure $1 \mathrm{~b}$ ) presents 8 bands; three of them correspond to $A_{1}$ vibrational modes (at 166, 224 and $410 \mathrm{~cm}^{-1}$ ), whereas the other bands can be attributed to E vibrational modes (at 290, 370, 480, 524 and $615 \mathrm{~cm}^{-1}$ ). These results are in good agreement with those previously reported by other authors for $\mathrm{BiFeO}_{3}$ powders with just some slight differences, ${ }^{49,56-57}$ which may be attributed to the strain existing in the nanoparticles due to the mechanosynthesis process. ${ }^{56}$ From these results, it is clear that highly pure nanostructured $\mathrm{BiFeO}_{3}$ was obtained by direct mechanochemical reaction starting from $\mathrm{Bi}_{2} \mathrm{O}_{3}$ and $\mathrm{Fe}_{2} \mathrm{O}_{3}$.
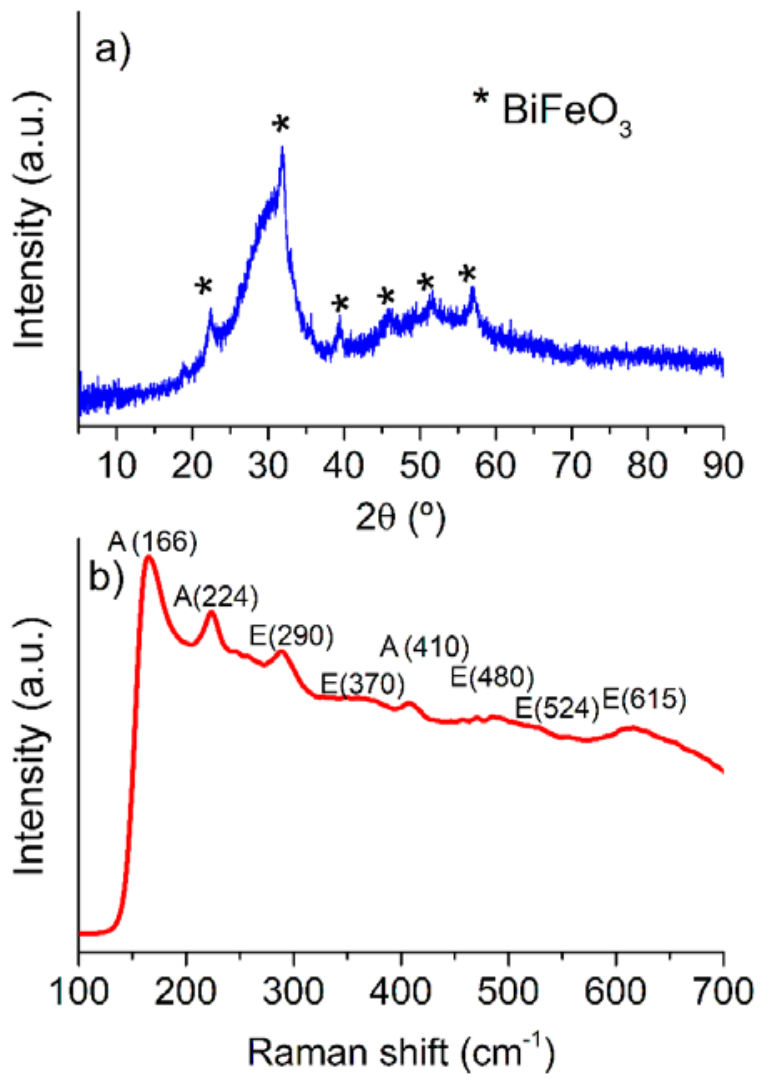

Figure 1. a) XRD pattern and b) Raman spectrum of the nanocrystalline mechanosynthesized $\mathrm{BiFeO}_{3}$ powder. 
HR-TEM analysis of the starting material is shown in Figure 2. The low magnification image (Figure 2a) corresponds to a highly aggregated sample characteristic of a material prepared by mechanosynthesis. In the high magnification image (Figure $2 b$ ) it was not possible to find well-defined fringes, and the selective area electron diffraction pattern (SAED) shows diffuse rings (Figure 2c) that could correspond to the planes (104) or (110), which d-spacings are quite close to each other with values of $0.281 \mathrm{~nm}$ and $0.278 \mathrm{~nm}$, respectively. All these results make clear that the starting sample is essentially composed of nanocrystalline $\mathrm{BiFeO}_{3}$.

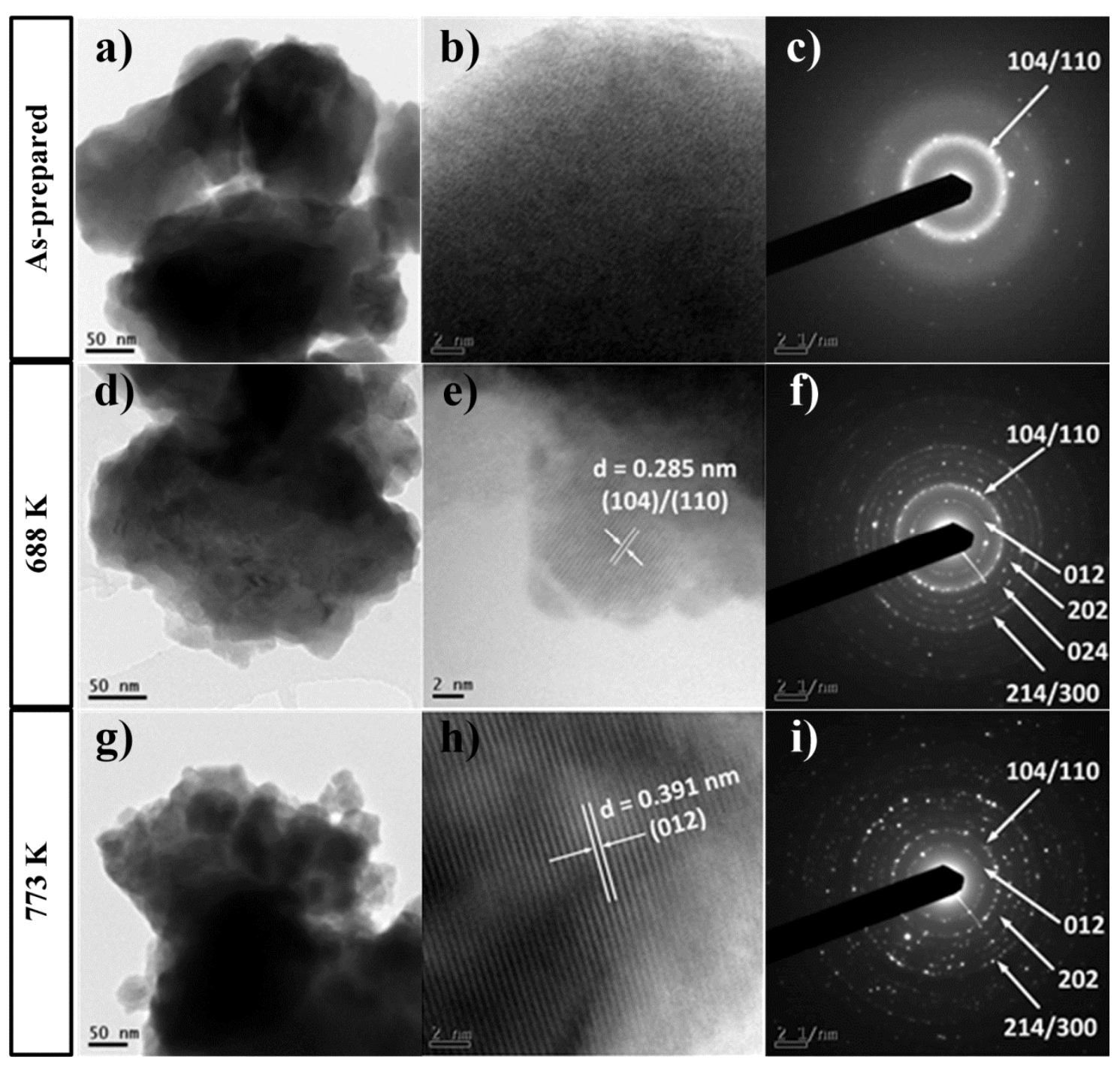

Figure 2. TEM micrographs, high resolution images and SAED patterns at different stages of crystallization of $\mathrm{BiFeO}_{3}$ : the as-prepared sample $(\mathrm{a}, \mathrm{b}, \mathrm{c})$, the sample heated at $688 \mathrm{~K}(\mathrm{~d}, \mathrm{e}, \mathrm{f})$ and at $773 \mathrm{~K}(\mathrm{~g}, \mathrm{~h}, \mathrm{i})$. 
A combination of different techniques was used to study the crystallization and crystal growth of the nanocrystalline $\mathrm{BiFeO}_{3}$ powder as a function of temperature. The crystallization and crystal growth was first followed by temperature dependent X-Ray diffraction, imposing a stepwise heating of $10 \mathrm{~K} \mathrm{~min}^{-1}$. Figure $3 \mathrm{a}$ shows selected in situ XRD patterns registered in the temperature range from $298 \mathrm{~K}$ to $973 \mathrm{~K}$ and in the $2 \theta$ range from $20^{\circ}$ to $60^{\circ}$. The peaks of the XRD patterns grow upon heating, although broad peaks are observed until $673 \mathrm{~K}$. From this temperature, the peaks appear narrower and from 773 $\mathrm{K}$ the two overlapped peaks at $\sim 32^{\circ}$ corresponding to the characteristic rhombohedral $\mathrm{R} 3 \mathrm{c}$ phase of $\mathrm{BiFeO}_{3}$ can be clearly distinguished. Further analysis of the temperature dependent X-Ray diffraction patterns was performed by means of Rietveld refinement and Le Bail fits, in order to obtain the amount of crystalline material and the crystallite size as a function of temperature, respectively. Figure $3 \mathrm{~b}$ shows the obtained crystallite size and crystallinity of the $\mathrm{BiFeO}_{3}$ powders. The crystallite size shows a steady rise almost in the entire temperature range studied here. Thus, from the $9 \mathrm{~nm}$ starting value at room temperature, it reaches about $27 \mathrm{~nm}$ at $673 \mathrm{~K}$. Further heating produces an additional increase that is more significant for temperatures above $900 \mathrm{~K}$, reaching a maximum value of $71 \mathrm{~nm}$ at $973 \mathrm{~K}$. The evolution of the crystallinity of the nanocrystalline material with temperature follows a quite different trend. Thus, the $\sim 9 \%$ crystallinity at room temperature only increases up to $18 \%$ at $598 \mathrm{~K}$, while it is followed by a dramatic increase until reaching full crystallinity at about $793 \mathrm{~K}$.

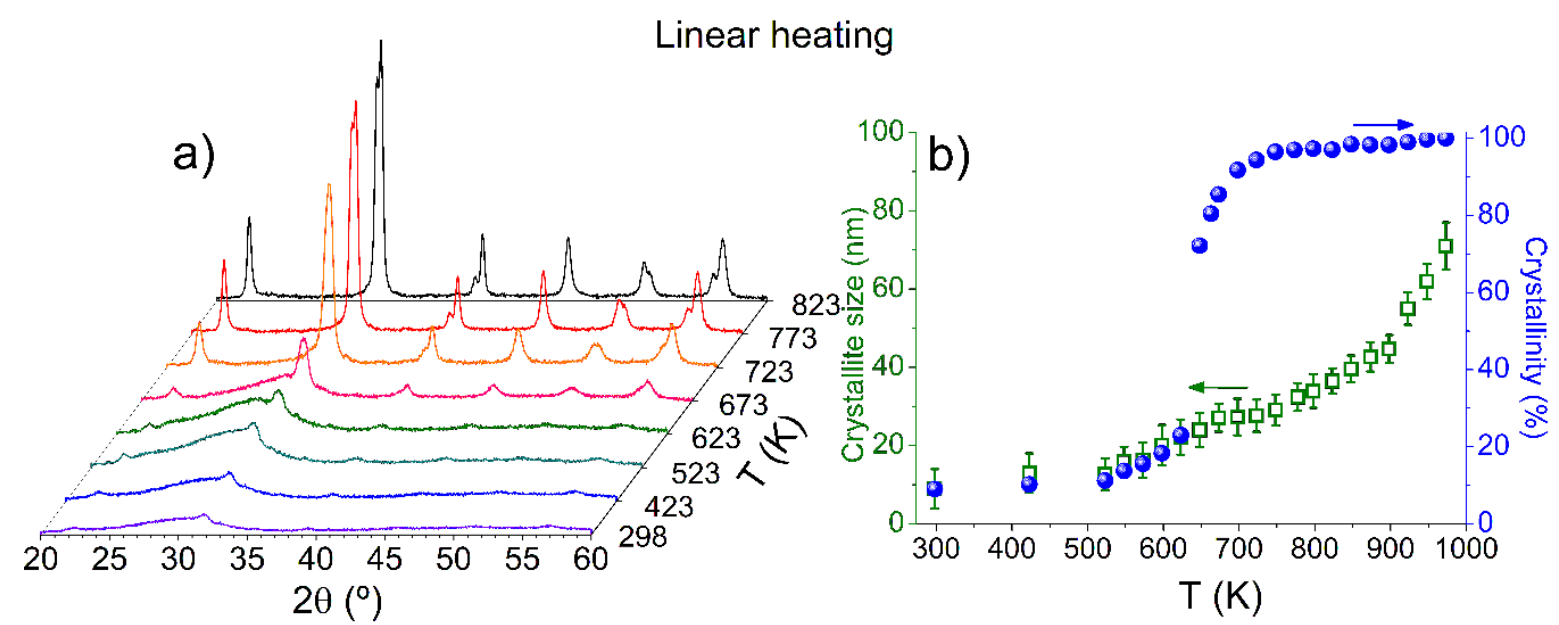

Figure 3. a) Selected X-ray diffraction patterns collected in situ in the temperature range 298-973

$\mathrm{K}$ for the nanocrystalline $\mathrm{BiFeO}_{3}$ powders. b) Crystallite size and crystallinity as a function of temperature, as obtained from the analysis of the XRD. 
High temperature X-ray diffraction experiments under isothermal conditions were also performed. In all these experiments, samples were heated to the desired temperatures at 10 $\mathrm{K} \min ^{-1}$, which is close to the maximum heating rate of the instrument, and the sample temperature was maintained at the temperature during the diffraction measurements. The XRD patterns were continuously recorded for $2 \mathrm{~h}$ in the $2 \theta$ range from $20^{\circ}$ to $60^{\circ}$, with a time per scan of $\sim 6.3 \mathrm{~min}$. Figure $4 \mathrm{a}$ shows some selected in situ X-ray diffraction patterns collected at different treatment times at $663 \mathrm{~K}$. The calculated crystallite sizes and \% crystallinity are presented in Figure 4b. Similar results for $653 \mathrm{~K}$ and $673 \mathrm{~K}$ are included in the Supplementary Information (Figures S1 and S2). From these results, it is quite clear that the crystallite size remains almost constant during the entire isothermal treatment while the $\%$ crystallinity increases as a function of time.

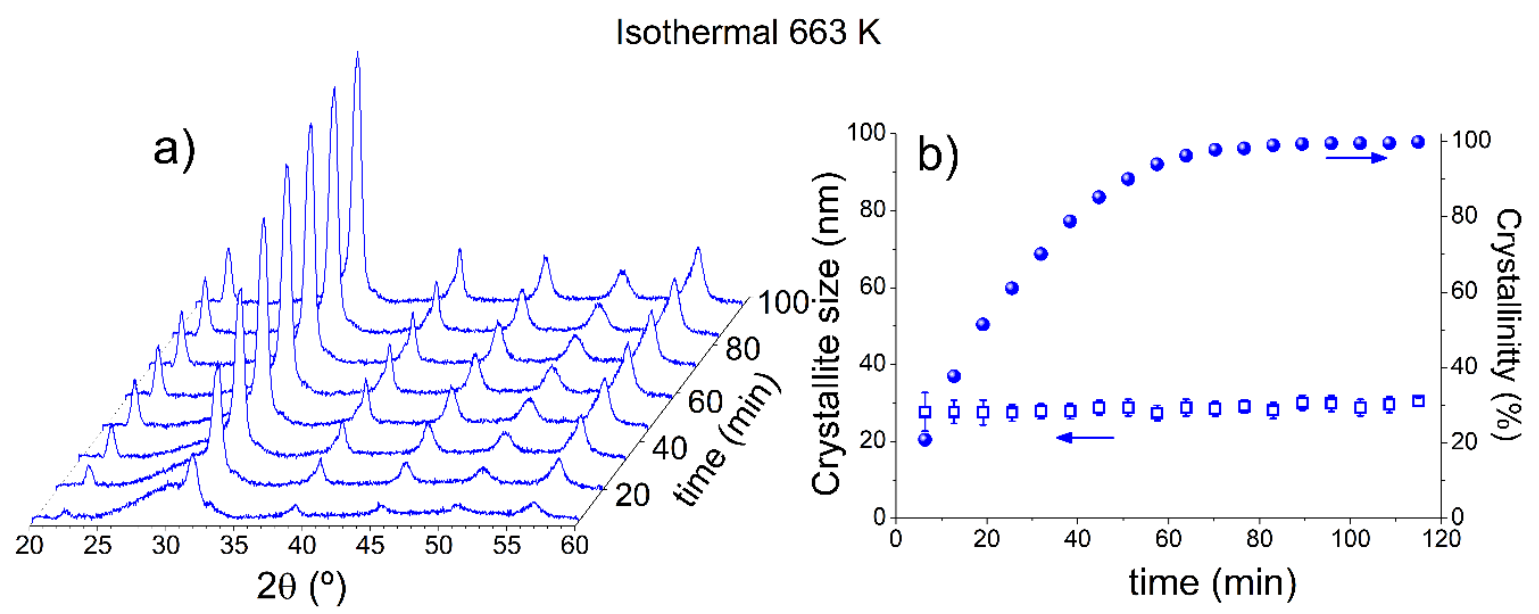

Figure 4. a) Selected X-ray diffraction patterns collected in situ as a function of time at a constant temperature of $663 \mathrm{~K}$ for the nanocrystalline $\mathrm{BiFeO}_{3}$ powder. b) Crystallite size and crystallinity as a function of time, as obtained from the analysis of the XRD patterns.

The crystallization of the material was also studied by DSC at different $\beta$, with the objective of complementing the XRD analyses. Figure 5 shows the as obtained DSC traces recorded at $\beta=2.5,5,7.5,10$ and $12.5 \mathrm{~K} \mathrm{~min}^{-1}$. In every case, an exothermic single-peak of crystallization can be observed from $650 \mathrm{~K}$ to $730 \mathrm{~K}$, which is in good agreement with the temperature range observed by XRD for the increase of the \% crystallinity. The peak maximum shifts to higher temperatures with $\beta$, which is characteristic of kinetically controlled processes. Table 1 lists the enthalpy of crystallization calculated by numerical integration of each DSC peak at different $\beta$. It can be clearly observed that the values are approximately constant, which is an indication that the crystallization of the material from 
9\% (initial degree of crystallization, obtained by Rietveld refinement for the as-prepared sample) to $100 \%$, takes place in every case. The average crystallization enthalpy of $\mathrm{BiFeO}_{3}$ associated to the crystallization from $9 \%$ to $100 \%, \Delta \mathrm{H}_{9-100}$ is $43.0 \pm 0.7 \mathrm{~J} \mathrm{~g}^{-1}$. Thus, the total crystallization enthalpy ( $0 \%$ to $100 \%$ crystallization) would correspond to $47.3 \mathrm{~J} \mathrm{~g}^{-1}$.

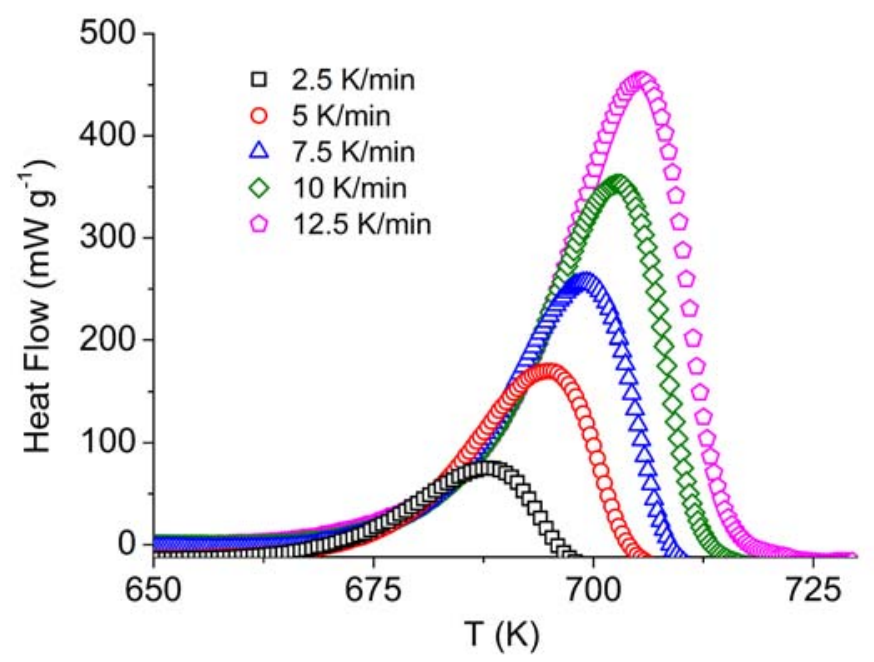

Figure 5. DSC experimental curves, recorded at different $\beta$, corresponding to the crystallization of nanocrystalline mechanosynthesized $\mathrm{BiFeO}_{3}$ powders.

Table 1. Enthalpy associated to the crystallization from $9 \%$ to $100 \%, \Delta \mathrm{H}_{9-100}$, of nanocrystalline $\mathrm{BiFeO}_{3}$, calculated from the DSC curves for each $\beta$.

\begin{tabular}{|c|c|}
\hline$\beta\left(\mathrm{K} \mathrm{min}^{-1}\right)$ & $\Delta \mathrm{H}_{9-100}\left(\mathrm{~J} \mathrm{~g}^{-1}\right)$ \\
\hline 2.5 & 43.8 \\
\hline 5 & 43.1 \\
\hline 7.5 & 43.5 \\
\hline 10 & 41.9 \\
\hline 12.5 & 42.9 \\
\hline
\end{tabular}

The microstructure of the nanocrystalline $\mathrm{BiFeO}_{3}$ powders at different stages of crystallization was studied by HR-TEM. In addition to the as prepared $\mathrm{BiFeO}_{3}$ nanocrystalline powder, samples at two stages of crystallization were prepared in the DSC: a sample heated to $688 \mathrm{~K}$, which corresponds to a crystallization of $86 \%$ according to the information obtained by XRD, and a sample heated to $773 \mathrm{~K}$, temperature at which full crystallization was achieved. The low magnification images (Figures $2 \mathrm{~d}$ and $2 \mathrm{~g}$ ) show that the heated samples retain the highly aggregated microstructure of the prepared material 
(Figure 2a). When the sample is heated up, the degree of crystallization increases, as also observed by temperature dependent XRD, and a clear evolution can be seen in the SAED patterns, where the diffuse rings progressively become sharper and composed of more defined spots, characteristic of a crystalline material (Figures $2 c, 2 f$ and $2 i$ ). For the sample heated up to $688 \mathrm{~K}$, the high resolution image (Figure 2e) shows a detail of an elongated particle of approximately $22 \mathrm{~nm}$ in the long axis, which is in good agreement with the crystallite size obtained from the in situ XRD patterns (Figure 3). The d-spacing for the lattice fringe of this crystallite is $0.285 \mathrm{~nm}$, which can be attributed to either plane (104) or (110) whose d-spacings are $0.281 \mathrm{~nm}$ and $0.278 \mathrm{~nm}$, respectively, as stated above. The sample heated at $773 \mathrm{~K}$ presents some crystalline nanoparticles with a size up to $30 \mathrm{~nm}$, which is in reasonable agreement with the crystallite size obtained by the Le Bail method from the XRD data. Additionally, for this sample larger crystalline areas are observed (Figure $2 \mathrm{~h}$ ). In this case, the d-spacing for the lattice fringes observed is $0.391 \mathrm{~nm}$, which is very close to the d-spacing for the plane (012), whose value is $0.396 \mathrm{~nm}$.

\subsection{Kinetics of crystallization of nanocrystalline $\mathrm{BiFeO}_{3}$}

The kinetic analysis of the crystallization of the nanocrystalline $\mathrm{BiFeO}_{3}$ powders was firstly performed under isothermal conditions from the $\%$ crystallinity determined from in situ high temperature X-Ray diffraction patterns at $653 \mathrm{~K}, 663 \mathrm{~K}$ and $673 \mathrm{~K}$, respectively, (Figure 4 and Figures S1 and S2 in the Supplementary Information). It is important to mention that one of the main issues of the isothermal method is the difficulty of defining the onset of the process because, ideally, the sample should be heated quickly enough to avoid the process to start before the desired temperature is reached. ${ }^{58}$ This is especially difficult in this case due to the maximum $\beta$ allowed by the high temperature chamber. However, this technical limitation is solved for these experiments since the Rietveld analysis of the first XRD pattern for each isotherm gives the degree of crystallinity of the sample only $\sim 6.3 \mathrm{~min}$ after the temperature is reached, and this value is taken as the onset. Thus, the values of crystallinity of the samples after the first scan were $18.9 \%, 20.9 \%$ and $35.9 \%$ for the isotherms at $653 \mathrm{~K}, 663 \mathrm{~K}$ and $673 \mathrm{~K}$, respectively. These values were determined considering the initial degree of crystallinity of $9 \%$ calculated by Rietveld refinement of the starting sample. Therefore, the degree of conversion as a function of time $\left(\alpha_{t}\right)$ for each isotherm was calculated normalizing the values of crystallinity from $9 \%$ to $100 \%$. Figure 6 presents the obtained $\alpha$-time curves. 


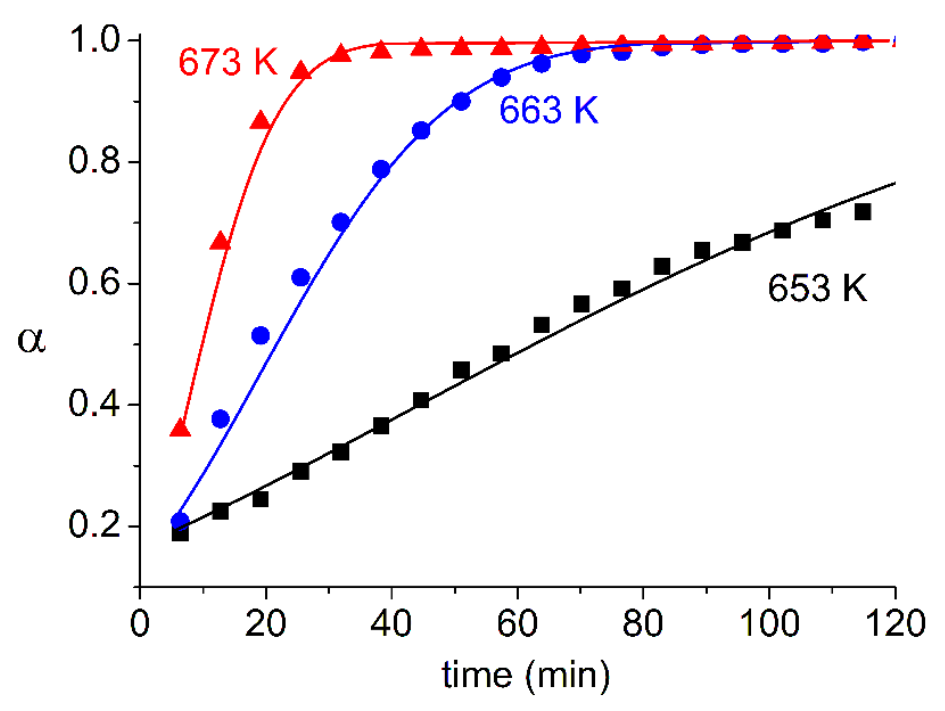

Figure 6. Experimental $\alpha$-time curves (dots) corresponding to the crystallization of nanocrystalline mechanosynthesized $\mathrm{BiFeO}_{3}$ powders, followed by XRD patterns recorded at 653,663 and $673 \mathrm{~K}$. The curves simulated using the kinetic parameters obtained from the analysis are plotted as solid lines.

The kinetic analysis of the curves in Figure 6 was performed using the isothermal method. ${ }^{59}$ This method consists of integrating the kinetic equation generally used for the reaction rate of solid-state processes:

$$
\frac{d \alpha}{d t}=k f(\alpha)
$$

where $\alpha$ is the degree of conversion, $d \alpha / d t$ is the reaction rate, $f(\alpha)$ is an algebraic equation that is usually associated with a physical model that describes the kinetics of the solid-state process and $k$ is the rate constant that is usually defined by an Arrhenius expression such as $\mathrm{Ae}^{-\mathrm{Ea} / \mathrm{RT}}$. In this expression, $\mathrm{A}$ is the pre-exponential factor, $\mathrm{E}_{\mathrm{a}}$ is the activation energy, $\mathrm{T}$ is the temperature and $\mathrm{R}$ is the gas constant.

Under isothermal conditions the term $k$ is a constant, and equation (1) can be integrated:

$$
\int_{0}^{\alpha} \frac{d \alpha}{f(\alpha)}=k \int_{0}^{t} d t
$$


Equation (2) can be also expressed as:

$$
g(\alpha)=k t
$$

The plot of $g(\alpha)$ versus the process time for the experimental curves provides straight lines if the selected kinetic model is correct, and the slope of these lines corresponds to the rate constant, $k$, for every isotherm. Table $\mathrm{S} 1$ includes the most common expressions found in literature for $f(\alpha)$ and $g(\alpha)$.

The plots of $\mathrm{g}(\alpha)$ versus time (equation (3)) for each isotherm in Figure 6 were built assuming eight of the most used kinetic models in literature for $f(\alpha)$ : interface controlled $(\mathrm{R} 2, \mathrm{R} 3)$, random nucleation and growth of nuclei or Avrami-Erofeev (A1, A1.5, A2, A3), and two-dimensional and three-dimensional diffusion controlled (D2, D4).

The best linear fits to the plots were obtained for the Avrami-Erofeev kinetic models, and specifically, for the A2 kinetic model. Figure 7a shows the linear fits obtained for the three studied isotherms considering the A2 kinetic model, from which slopes the rate constant (k) for every isotherm was obtained.

Given the Arrhenius dependence of $k$ and rearranging in logarithmic form, equation (4) is obtained:

$$
\ln k=\ln A-\frac{E_{a}}{R T}
$$

The activation energy of the process can be calculated from the slope of the plot of the logarithm of the rate constants versus the reverse of their corresponding temperatures, and the pre-exponential factor, A, is obtained from the intercept.

Figure $7 \mathrm{~b}$ presents the plot of $\ln (k)$ versus the inverse of temperature. According to equation 4 , the resulting values of activation energy, $E_{a}$, and preexponential factor, $A$, are $379.0 \pm 7.0 \mathrm{~kJ} \mathrm{~mol}^{-1}$ and $1.3( \pm 0.2) \times 10^{28} \mathrm{~min}^{-1}$, respectively. The reliability of the obtained kinetic parameters was tested comparing the experimental curves in Figure 6 with simulated kinetic curves constructed using these parameters, the temperatures employed for the experiments and the obtained A2 kinetic model. The simulations were carried out by integrating the general kinetic equation and using the fourth-order numerical integration Runge-Kutta method. As may be seen in Figure 6, the simulated and experimental curves are in very good agreement, which proves the validity of the kinetic parameters obtained by the isothermal method. 


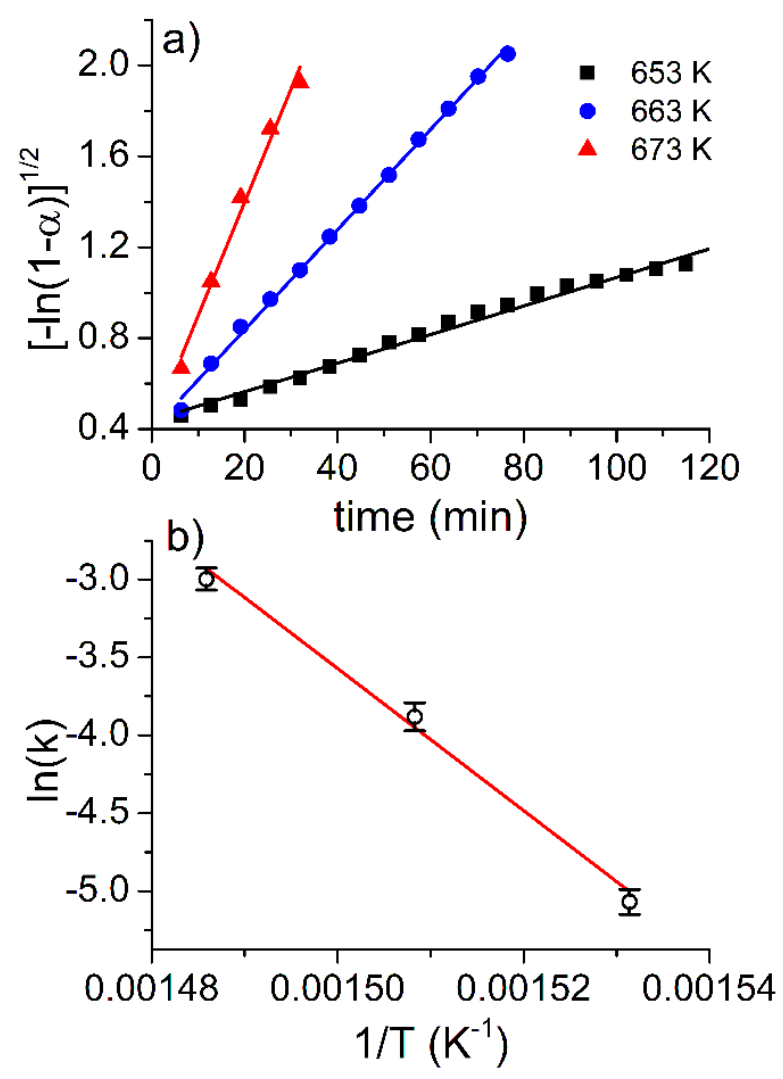

Figure 7. a) $g(\alpha)$ versus crystallization time for the experimental $\alpha$-time curves presented in Figure 6, considering A2 kinetic model. The linear fits obtained for the three isotherms are also included. b) Logarithm of $\mathrm{k}$ against the reverse temperature.

The kinetics of crystallization was also studied from the curves obtained by differential scanning calorimetry (Figure 5) and the results were compared with those calculated from the XRD experiments. The degree of conversion was calculated from the DSC curves taking into account the results obtained in the XRD experiments. Thus, an initial degree of conversion of 0.09 was considered since the initial value of crystallinity is $9 \%$ as calculated by Rietveld refinement of the starting sample. Therefore, the total area enclosed in the DSC peaks corresponds to $0.09 \leq \alpha \leq 1.00$. Figure 8 a shows the $\alpha$-T plots, obtained by numerical integration of the normalized DSC plots. Figure $8 \mathrm{~b}$ presents the reaction rate $(\mathrm{d} \alpha / \mathrm{dt})$, for each experiment, as a function of temperature, calculated differentiating the $\alpha$ T curves with respect to the time. 


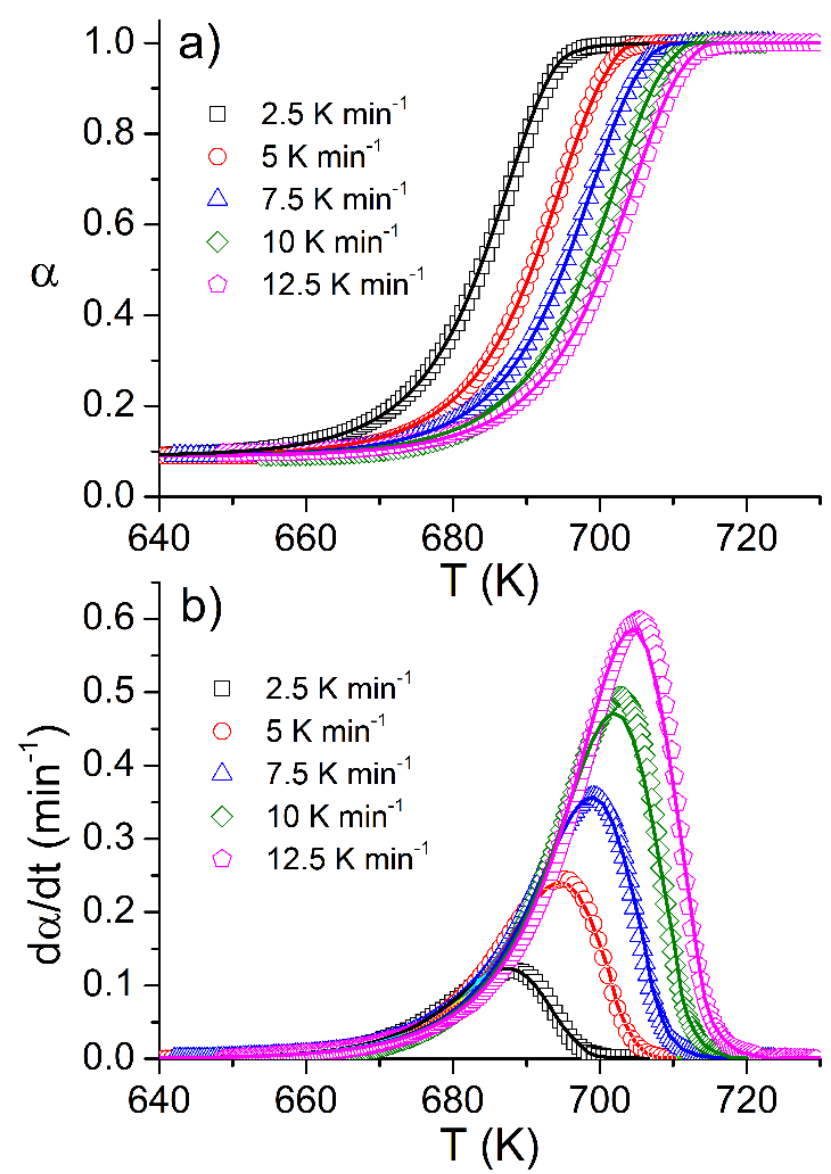

Figure 8. Normalized a) $\alpha-T$ and b) $d \alpha / d t-T$ plots corresponding to the crystallization of nanocrystalline mechanosynthesized $\mathrm{BiFeO}_{3}$ powders (dotted lines). The curves simulated using the kinetic parameters obtained from the kinetic analysis are plotted as solid lines.

The activation energy of crystallization as a function of the degree of conversion was calculated by the Friedman isoconversional method, which allows the determination of the activation energy, $E_{a}$, of the solid-state processes from a set of $\alpha-T$ plots recorded at different $\beta$ without any previous assumption on the kinetic model. ${ }^{60-63}$ Rearranging equation (1) in logarithmic form:

$$
\ln \left(\frac{d \alpha}{d t}\right)=\ln (A f(\alpha))-\frac{E_{a}}{R T}
$$

At a determinate value of $\alpha, f(\alpha)$ is constant and the activation energy as a function of $\alpha$ can be determined from the slope of the left-hand side of equation (5) versus the inverse of the temperature. All experimental curves included in Figure 8 were analyzed simultaneously. Figure 9 presents the activation energy values obtained as a function of $\alpha$. It can be observed that $\mathrm{E}_{\mathrm{a}}$ is reasonably constant during the entire process, with an average 
value of $371 \pm 7 \mathrm{~kJ} \mathrm{~mol}^{-1}$, which is in good agreement with the activation energy calculated by means of the isothermal method applied to the XRD data. This result suggests that the crystallization of the nanocrystalline $\mathrm{BiFeO}_{3}$ powders takes place through a single step.

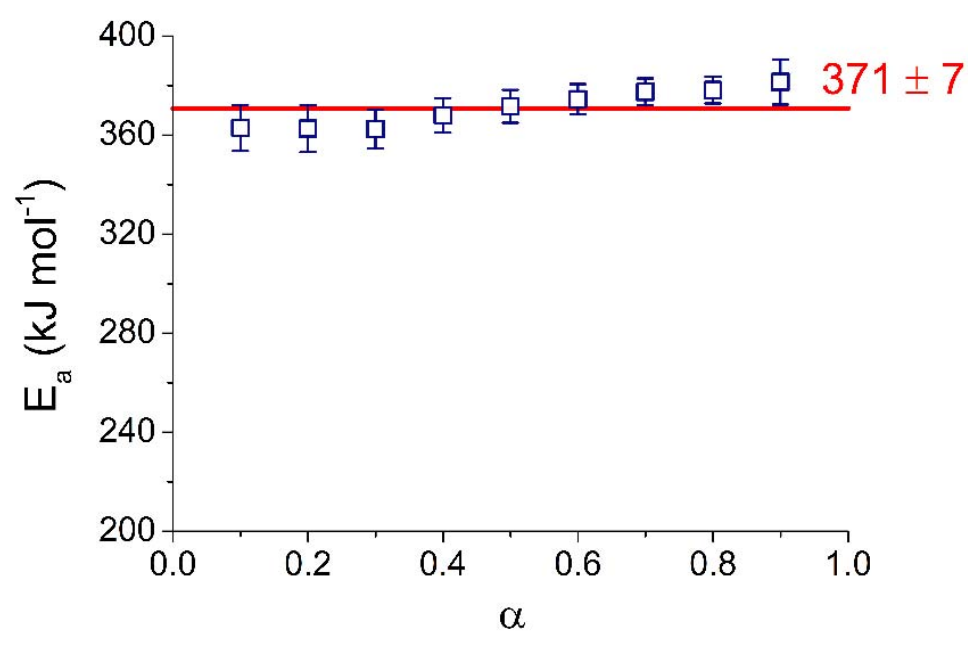

Figure 9. Activation energy values as a function of $\alpha$, obtained from the Friedman isoconversional analysis of the experimental curves shown in Figure 8.

The combined kinetic analysis was applied simultaneously to all the experimental curves presented in Figure 8 in order to obtain the kinetic parameters for the crystallization of the nanocrystalline $\mathrm{BiFeO}_{3}$ powders, and with the objective of comparing and complementing the results obtained by the isothermal method applied to the XRD data. The method consists of the analysis of a set of experimental data measured under different temperature programs, without any previous assumption neither of the kinetic parameters or the kinetic model of the process. ${ }^{64-66}$ This method uses the modified Sestak-Berggren equation as a fitting function:

$$
f(\alpha)=c(1-\alpha)^{n} \alpha^{m}
$$

Thus, by adjusting de values of $\mathrm{c}, \mathrm{n}$, and $\mathrm{m}$, this empirical equation can fit all the kinetic models proposed in literature for describing solid state reactions, even taking into account deviations from ideal models. ${ }^{64,} 66$ Taking logarithms into equation (1), rearranging terms and replacing equation (6), the expression for the combined kinetic analysis is obtained:

$$
\ln \left(\frac{d \alpha / d t}{(1-\alpha)^{n} \alpha^{m}}\right)=\ln (c A)-\frac{E_{a}}{R T}
$$


The set of experimental data was substituted into equation (7) and the left-hand side of the equation was plotted against the reverse temperature, as shown in Figure 10. Then, the parameters $\mathrm{n}$ and $\mathrm{m}$ that provide the best linearity (maximum Pearson linear correlation coefficient, r) to the plot of the left-hand side of equation (7) versus the inverse of temperature were determined by an optimization procedure. The values of $\mathrm{n}$ and $\mathrm{m}$ obtained were 0.857 and 0.545 , respectively. Once the values of $\mathrm{n}$ and $\mathrm{m}$ that maximized $\mathrm{r}$ were found, the slope of the plot led to an activation energy of $369 \pm 8 \mathrm{~kJ} \mathrm{~mol}^{-1}$ and the intercept to a value of $\mathrm{cA}$ of $(4.6 \pm 0.4) \times 10^{27} \mathrm{~min}^{-1}$. The activation energy is similar to that obtained by the Friedman isoconversional method and also close to the activation energy calculated from the XRD data using the isothermal method. This is an indication that the same phenomenon has been measured by XRD and DSC (the crystallization of the sample in this case), although the physical properties measured from both techniques are different.

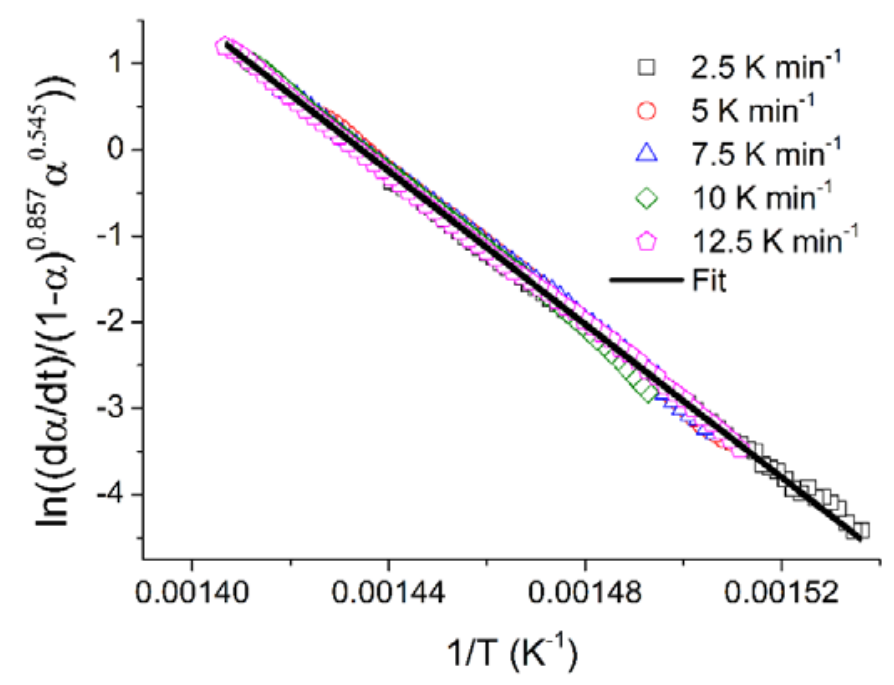

Figure 10. Combined kinetic analysis plot of the experimental kinetic curves presented in Figure 8 for the crystallization of nanocrystalline mechanosynthesized $\mathrm{BiFeO}_{3}$ powders.

The $f(\alpha)$ function obtained from the combined kinetic analysis, $f(\alpha)=(1-\alpha)^{0.857} \alpha^{0.545}$, was compared with some of the most commonly used $f(\alpha)$ theoretical functions for describing solid state processes, in order to determine the kinetic model obeyed by the crystallization process. As shown in Figure 11, these curves are normalized at $\alpha=0.5$, for a better distinction between the different models, and are represented versus the degree of conversion, $\alpha$. It is clearly observed that the experimental $f(\alpha)$ function is quite similar to 
the theoretical curve corresponding to the Avrami-Erofeev A2 kinetic model, which again is in agreement with the results obtained by the isothermal method. However, unlike the isothermal method, for the combined kinetic analysis the kinetic model is not previously assumed, but it results from the analysis.

In the general equation for Avrami type models, the parameter $\mathrm{n}$ depends on the nucleation and growth mechanism and dimensionality. Table 2 summarizes the corresponding $\mathrm{n}$ parameters for the different nucleation and growth mechanisms, as taken from ref. [66]. From a physical point of view, the Avrami-Erofeev nucleation and growth mechanism A2, obtained for the present process, can be formally interpreted as an instantaneous random nucleation and two-dimensional crystallization of the material. ${ }^{67-69}$

Table 2. Values of the exponent $\mathrm{n}$ for the Avrami equation for different kinds of reaction mechanisms.

\begin{tabular}{|c|c|c|c|}
\hline Type of nucleation & $\begin{array}{c}\text { Geometry of } \\
\text { nuclei and their } \\
\text { subsequent growth }\end{array}$ & $\begin{array}{c}\text { Phase } \\
\text { boundary } \\
\text { controlled }\end{array}$ & $\begin{array}{l}\text { Diffusion } \\
\text { controlled }\end{array}$ \\
\hline \multirow{6}{*}{$\begin{array}{l}\text { Instantaneous } \\
\text { nucleation (saturation } \\
\text { of sites capable of } \\
\text { nucleation prior to } \\
\text { growth) }\end{array}$} & \multicolumn{3}{|l|}{ Bulk mechanism } \\
\hline & $\begin{array}{l}\text { One dimensional } \\
\text { growth }\end{array}$ & 1 & 0.5 \\
\hline & $\begin{array}{l}\text { Two-dimensional } \\
\text { growth }\end{array}$ & 2 & 1 \\
\hline & $\begin{array}{c}\text { Three-dimensional } \\
\text { growth }\end{array}$ & 3 & 1.5 \\
\hline & \multicolumn{3}{|l|}{ Surface mechanism } \\
\hline & $\begin{array}{l}\text { Two-dimensional } \\
\text { growth }\end{array}$ & $\sim 2$ & 1 \\
\hline \multirow{6}{*}{$\begin{array}{c}\text { Constant rate of } \\
\text { homogeneous } \\
\text { nucleation during the } \\
\text { process }\end{array}$} & \multicolumn{3}{|l|}{ Bulk mechanism } \\
\hline & $\begin{array}{c}\text { One-dimensional } \\
\text { growth }\end{array}$ & 2 & 1.5 \\
\hline & $\begin{array}{c}\text { Two-dimensional } \\
\text { growth }\end{array}$ & 3 & 2 \\
\hline & $\begin{array}{l}\text { Three-dimensional } \\
\text { growth }\end{array}$ & 4 & 2.5 \\
\hline & \multicolumn{3}{|l|}{ Surface mechanism } \\
\hline & $\begin{array}{l}\text { Two-dimensional } \\
\text { growth }\end{array}$ & $\sim 3$ & $\sim 2$ \\
\hline
\end{tabular}




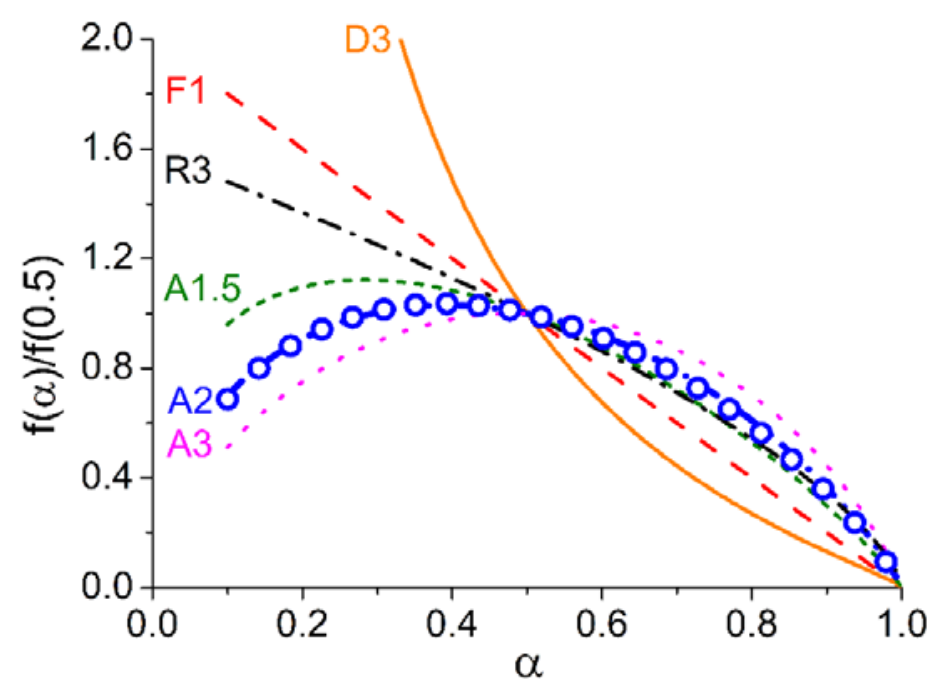

Figure 11. Comparison of some ideal kinetic models (lines) with the $f(\alpha)$ function resulting from the combined kinetic analysis (dots) of the crystallization of nanocrystalline mechanosynthesized $\mathrm{BiFeO}_{3}$ powders.

In order to check the reliability of the kinetic parameters calculated by the combined kinetic analysis method, these kinetic parameters were used to simulate kinetic curves considering the same $\beta$ employed to register the experimental DSC curves. The simulations were performed by integration of the general kinetic equation, in the same way than for the isothermal analysis. Figure $8 \mathrm{a}$ shows that the $\alpha$-T curves and the numerically simulated curves match very well for every $\beta$, which demonstrates the validity of the kinetic parameters. Additionally, and as a step forward, the simulated integral curves were differentiated with respect to time and compared with the experimental normalized $\mathrm{d} \alpha / \mathrm{dt}-\mathrm{T}$ curves (Figure $8 b$ ). The excellent match obtained between the simulated and experimental curves further proves the reliability of the kinetic parameters.

It is worthy to note that for the kinetic analysis of the DSC curves, it has been required a proper definition of $\alpha$, which cannot be directly done by DSC because the starting degree of crystallinity of the samples cannot be assessed from this technique. This is an important issue as different results can be obtained if $\alpha$ values are defined in a different way. To further illustrate this issue, the kinetic analysis of DSC data has been also performed considering that the initial degree of crystallization of the sample is 0 and the final degree of crystallization is $100 \%$ in the temperature range in which the DSC peaks are observed (this is quite a conventional procedure when additional experimental data is lacking). 
Interestingly, from the combined kinetic analysis, the resulting values of activation energy $\left(\mathrm{E}_{\mathrm{a}}=370 \pm 8 \mathrm{~kJ} \mathrm{~mol}^{-1}\right)$ and $\mathrm{cA}\left((4.2 \pm 0.5) \times 10^{27} \mathrm{~min}^{-1}\right)$ are very similar to those calculated when the values of $\alpha$ are properly defined. However, the values of $n$ and $m$ of the modified $f(\alpha)$ Sestak-Berggren equation are different: $n=0.779$ and $m=0.314$, which leads to a quite different kinetic model, A1.5, when $\mathrm{f}(\alpha)$ is compared with the theoretical $f(\alpha)$ functions, as may be seen in Figure 12. Moreover, the same kinetic model is obtained if the kinetic analysis of the XRD data is carried out considering this normalization of $\alpha$. Therefore, an incorrect definition of the degree of conversion leads to erroneous kinetic models, which deviations from the real one may depend on the range of $\alpha$ values considered.

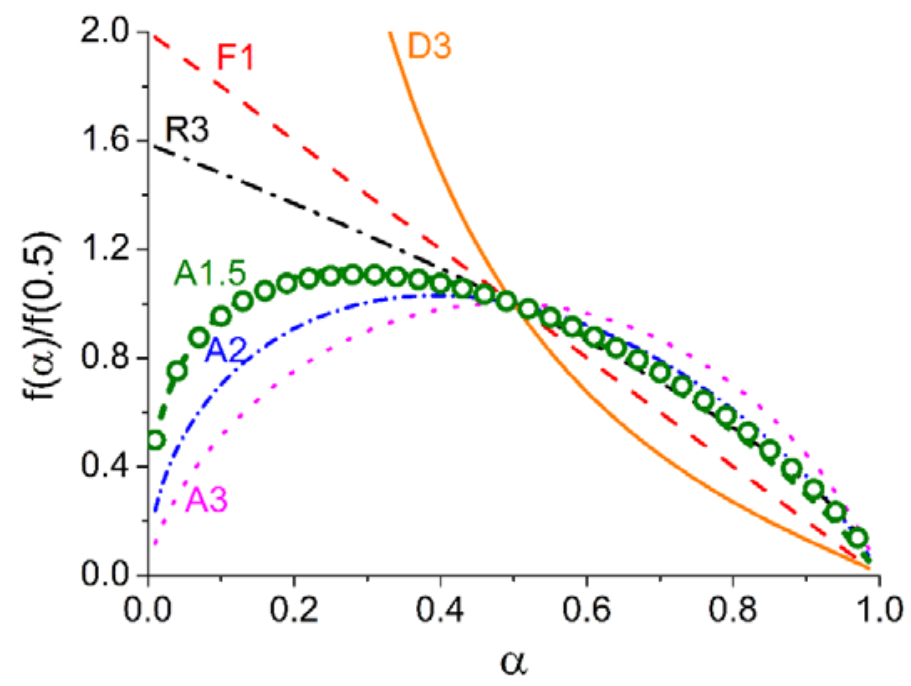

Figure 12. Comparison of some ideal kinetic models (lines) with the $f(\alpha)$ function resulting from the combined kinetic analysis (dots) of the crystallization process if the degree of conversion is defined as $0 \leq \alpha \leq 1$ instead of the real range $0.09 \leq \alpha \leq 1$.

\section{Conclusions}

A complete description of the thermal crystallization event of nanocrystalline $\mathrm{BiFeO}_{3}$ has been performed in this work by a combination of the information obtained from three different techniques: in situ high temperature X-ray diffraction, transmission electron microscopy and differential scanning calorimetry. From the in situ high temperature X-ray diffraction data, the amount of crystalline material, as calculated by means of Rietveld refinement, for the as prepared sample was estimated at $9 \%$. The crystallite size suffers a steady increase with temperature in the entire studied range that does not seem to be 
directly related to the \%crystallinity in the sample. The TEM data confirms the nanocrystalline (amorphous) nature of the as-mechanosynthesised $\mathrm{BiFeO}_{3}$ powder since diffuse rings are observed in the SAED patterns. When the sample is heated up, the diffuse rings become sharper and composed of defined spots, characteristic of the increase in crystallinity. Moreover, high-resolution TEM shows better defined crystals with welldefined fringes as the treatment temperature increases. The differential scanning calorimetry traces complement the XRD and HR-TEM analyses. Single exothermic peaks corresponding to crystallization are obtained in the same temperature range at which the increase in crystallinity is observed by XRD.

The kinetic analysis of the crystallization has been carried out using experimental data obtained from high-temperature XRD, which gives an indirect measurement of the \%crystallinity, and DSC, which measures the heat flow attributed to the crystallization process. For both XRD and DSC data, it was required the information about the initial and final degree of crystallinity of the sample at the temperatures studied for a proper definition of the degree of conversion. Although both techniques, X-ray diffraction and DSC, measure totally different physical properties of the sample during heating, both experimental data correspond to the same process, i.e. crystallization of the sample, and yield almost identical kinetic parameters. Thus, the crystallization follows an A2 AvramiErofeev kinetic model with an activation energy of $369 \pm 8 \mathrm{~kJ} \mathrm{~mol}^{-1}$. This study highlights that a reliable crystallization kinetic analysis could be obtained from a combination of different physical measurements but the degrees of conversion should be properly defined.

\section{Acknowledgments}

The support from projects CTQ2014-52763-C2-1-R (MINECO-FEDER) and CTQ201783602-C2 (MINECO-FEDER) is acknowledged. The authors also thank VPPI-US for the AP current contract and the RyC program for PESJ contract. The facilities given by the Xray Service of the Innovation, Technology and Research Center of the University of Seville (CITIUS) for recording the XRD patterns at high temperature are gratefully acknowledged. 


\section{Supporting Information}

Selected X-ray diffraction patterns collected in situ as a function of time at constant temperatures of $653 \mathrm{~K}$ and $673 \mathrm{~K}$; corresponding crystallite size and crystallinity as a function of time, as obtained from the analysis of the XRD patterns.

\section{References}

(1) Mahamid, J.; Sharir, A.; Gur, D.; Zelzer, E.; Addadi, L.; Weiner, S. Bone mineralization proceeds through intracellular calcium phosphate loaded vesicles: A cryo-electron microscopy study. J. Struct. Biol. 2011, 174, 527-535.

(2) Whittaker, M. L.; Sun, W. H.; DeRocher, K. A.; Jayaraman, S.; Ceder, G.; Joester, D. Structural Basis for Metastability in Amorphous Calcium Barium Carbonate (ACBC). Adv. Funct. Mater. 2018, 28, 14. 1704202.

(3) Matsunuma, S.; Kagi, H.; Komatsu, K.; Maruyama, K.; Yoshino, T. Doping Incompatible Elements into Calcite through Amorphous Calcium Carbonate. Cryst. Growth Des. 2014, 14, 5344-5348.

(4) Zhang, H.; Banfield, J. F. Kinetics of Crystallization and Crystal Growth of Nanocrystalline Anatase in Nanometer-Sized Amorphous Titania. Chem. Mater. 2002, 14, 4145-4154.

(5) Kirsch, B. L.; Richman, E. K.; Riley, A. E.; Tolbert, S. H. In-situ X-ray diffraction study of the crystallization kinetics of mesoporous titania films. J. Phys. Chem. B 2004, 108, 12698-12706.

(6) Choi, S. Y.; Mamak, M.; Speakman, S.; Chopra, N.; Ozin, G. A. Evolution of nanocrystallinity in periodic mesoporous anatase thin films. Small 2005, 1, 226232.

(7) Bots, P.; Benning, L. G.; Rodriguez-Blanco, J. D.; Roncal-Herrero, T.; Shaw, S. Mechanistic Insights into the Crystallization of Amorphous Calcium Carbonate (ACC). Cryst. Growth Des. 2012, 12, 3806-3814.

(8) Fogg, A. M.; Price, S. J.; Francis, R. J.; O'Brien, S.; O'Hare, D. Determination of the kinetics of crystallisation of gibbsite using time resolved in situ energy dispersive powder X-ray diffraction. J. Mater. Chem. 2000, 10, 2355-2357. 
(9) Málek, J. Kinetic analysis of crystallization processes in amorphous materials. Thermochim. Acta 2000, 355, 239-253.

(10) Chen, B.; Momand, J.; Vermeulen, P. A.; Kooi, B. J. Crystallization Kinetics of Supercooled Liquid Ge-Sb Based on Ultrafast Calorimetry. Cryst. Growth Des. 2016, 16, 242-248.

(11) Svoboda, R.; Malek, J. Interpretation of crystallization kinetics results provided by DSC. Thermochim. Acta 2011, 526, 237-251.

(12) Caze, C.; Devaux, E.; Crespy, A.; Cavrot, J. P. A new method to determine the Avrami exponent by dsc studies of non-isothermal crystallization from the molten state. Polymer 1997, 38, 497-502.

(13) Vyazovkin, S.; Sbirrazzuoli, N. Isoconversional analysis of the nonisothermal crystallization of a polymer melt. Macromol. Rapid Commun. 2002, 23, 766-770.

(14) Bartak, J.; Martinkova, S.; Malek, J. Crystal Growth Kinetics in Se-Te Bulk Glasses. Cryst. Growth Des. 2015, 15, 4287-4295.

(15) Choi, Y.; Jung, M.; Lee, Y. K. Effect of Heating Rate on the Activation Energy for Crystallization of Amorphous $\mathrm{Ge}_{2} \mathrm{Sb}_{2} \mathrm{Te}_{5}$ Thin Film. Electrochem. Solid State Lett. 2009, 12, F17-F19.

(16) Orava, J.; Greer, A. L.; Gholipour, B.; Hewak, D. W.; Smith, C. E. Characterization of supercooled liquid $\mathrm{Ge}_{2} \mathrm{Sb}_{2} \mathrm{Te}_{5}$ and its crystallization by ultrafast-heating calorimetry. Nat. Mater. 2012, 11, 279-283.

(17) Jang, J. S. C.; Tsao, S. F.; Chang, L. J.; Chen, G. J.; Huang, J. C. Crystallization kinetics of the $\mathrm{Zr}_{61} \mathrm{Al}_{7.5} \mathrm{Cu}_{17.5} \mathrm{Ni}_{10} \mathrm{Si}_{4}$ alloy using isothermal DSC and TEM observation. J. Non-Cryst. Solids 2006, 352, 71-77.

(18) Kooi, B. J.; Groot, W. M. G.; De Hosson, J. T. M. In situ transmission electron microscopy study of the crystallization of $\mathrm{Ge}_{2} \mathrm{Sb}_{2} \mathrm{Te}_{5}$. J. Appl. Phys. 2004, 95, 924932.

(19) Winseck, M. M.; Cheng, H. Y.; Campbell, G. H.; Santala, M. K. Crystallization kinetics of the phase change material GeSb6 ${ }_{6} \mathrm{Te}$ measured with dynamic transmission electron microscopy. Dalton Trans. 2016, 45, 9988-9995.

(20) Stocker, W.; Schumacher, M.; Graff, S.; Thierry, A.; Wittmann, J. C.; Lotz, B. Epitaxial crystallization and AFM investigation of a frustrated polymer structure: Isotactic poly(propylene), beta phase. Macromolecules 1998, 31, 807-814.

(21) Di Lorenzo, M. L.; Silvestre, C. Non-isothermal crystallization of polymers. Prog. Polym. Sci. 1999, 24, 917-950. 
(22) Long, Y.; Shanks, R. A.; Stachurski, Z. H. Kinetics of polymer crystallization. Prog. Polym. Sci. 1995, 20, 651-701.

(23) Vyazovkin, S.; Sbirrazzuoli, N. Isoconversional kinetic analysis of thermally stimulated processes in polymers. Macromol. Rapid Commun. 2006, 27, 15151532.

(24) Fornes, T. D.; Paul, D. R. Crystallization behavior of nylon 6 nanocomposites. Polymer 2003, 44, 3945-3961.

(25) Paul, D. R.; Robeson, L. M. Polymer nanotechnology: Nanocomposites. Polymer 2008, 49, 3187-3204.

(26) Codou, A.; Guigo, N.; van Berkel, J.; de Jong, E.; Sbirrazzuoli, N. Non-isothermal Crystallization Kinetics of Biobased Poly(ethylene 2,5-furandicarboxylate) Synthesized via the Direct Esterification Process. Macromol. Chem. Phys. 2014, 215, 2065-2074.

(27) Alamo, R. G.; Mandelkern, L. Crystallization kinetics of random ethylene copolymers. Macromolecules 1991, 24, 6480-6493.

(28) Clavaguera-Mora, M. T.; Clavaguera, N.; Crespo, D.; Pradell, T. Crystallisation kinetics and microstructure development in metallic systems. Prog. Mater. Sci. 2002, 47, 559-619.

(29) Ou, X.; Zhang, G. Q.; Xu, X.; Wang, L. N.; Liu, J. F.; Jiang, J. Z. Crystallization kinetics in $\mathrm{Cu}_{35} \mathrm{Ag}_{15} \mathrm{Zr}_{45} \mathrm{Al}_{15}$ metallic glass. J. Alloy. Compd. 2007, 441, 181-184.

(30) Tkatch, V. I.; Rassolov, S. G.; Moiseeva, T. N.; Popov, V. V. Analytical description of isothermal primary crystallization kinetics of glasses: $\mathrm{Fe}_{85} \mathrm{~B}_{15}$ amorphous alloy. J. Non-Cryst. Solids 2005, 351, 1658-1664.

(31) Abu El-Oyoun, M. A study of the crystallization kinetics of $\mathrm{Ge}_{20} \mathrm{Te}_{80}$ chalcogenide glass. J. Phys. D-Appl. Phys. 2000, 33, 2211-2217.

(32) Pustkova, P.; Zmrhalova, Z.; Malek, J. The particle size influence on crystallization kinetics of $\left(\mathrm{GeS}_{2}\right)_{0.1}\left(\mathrm{Sb}_{2} \mathrm{~S}_{3}\right)_{0.9}$ glass. Thermochim. Acta 2007, 466, 13-21.

(33) Elnaeim, A. M. A.; Aly, K. A.; Afify, N.; Abousehlly, A. M. Glass transition and crystallization kinetics of $\operatorname{In}_{\mathrm{x}}\left(\mathrm{Se}_{0.75} \mathrm{Te}_{0.25}\right)_{100-\mathrm{x}}$ chalcogenide glasses. J. Alloy. Compd. 2010, 491, 85-91.

(34) Sebastian, A.; Le Gallo, M.; Krebs, D. Crystal growth within a phase change memory cell. Nat. Commun. 2014, 5. 4314. 
(35) Huang, S. F.; Cao, P.; Li, Y.; Huang, Z. H.; Gao, W. Nucleation and Crystallization Kinetics of a Multicomponent Lithium Disilicate Glass by in Situ and Real-Time Synchrotron X-ray Diffraction. Cryst. Growth Des. 2013, 13, 4031-4038.

(36) Donald, I. W.; Metcalfe, B. L.; Gerrard, L. A.; Fong, S. K. The influence of $\mathrm{Ta}_{2} \mathrm{O}_{5}$ additions on the thermal properties and crystallization kinetics of a lithium zinc silicate glass. J. Non-Cryst. Solids 2008, 354, 301-310.

(37) Ahvenainen, P.; Kontro, I.; Svedström, K. Comparison of sample crystallinity determination methods by X-ray diffraction for challenging cellulose I materials. Cellulose 2016, 23, 1073-1086.

(38) Rodriguez-Blanco, J. D.; Shaw, S.; Benning, L. G. The kinetics and mechanisms of amorphous calcium carbonate (ACC) crystallization to calcite, via vaterite. Nanoscale 2011, 3, 265-271.

(39) Ozawa, T. Kinetics of non-isothermal crystallization. Polymer 1971, 12, 150-158.

(40) Lorenzo, A. T.; Arnal, M. L.; Albuerne, J.; Muller, A. J. DSC isothermal polymer crystallization kinetics measurements and the use of the Avrami equation to fit the data: Guidelines to avoid common problems. Polym. Test 2007, 26, 222-231.

(41) Pielichowska, K.; Dryzek, E.; Olejniczak, Z.; Pamula, E.; Pagacz, J. A study on the melting and crystallization of polyoxymethylene-copolymer/hydroxyapatite nanocomposites. Polym. Adv. Technol. 2013, 24, 318-330.

(42) Chen, W.; Moon, I. K.; Wunderlich, B. Study of crystallization kinetics by temperature-modulated DSC. Polymer 2000, 41, 4119-4125.

(43) Perejón, A.; Sánchez-Jiménez, P. E.; Criado, J. M.; Pérez-Maqueda, L. A. A Promising Approach to the Kinetics of Crystallization Processes: The Sample Controlled Thermal Analysis. J. Am. Ceram. Soc. 2017, 100, 1125-1133.

(44) Perez, A.; Lopez-Olmedo, J. P.; Farjas, J.; Roura, P. Isoconversional analysis of copper recrystallization. J. Therm. Anal. Calorim. 2016, 125, 667-672.

(45) Holba, P.; Sestak, J. Heat inertia and its role in thermal analysis. J. Therm. Anal. Calorim. 2015, 121, 303-307.

(46) Vyazovkin, S.; Chrissafis, K.; Di Lorenzo, M. L.; Koga, N.; Pijolat, M.; Roduit, B.; Sbirrazzuoli, N.; Sunol, J. J. ICTAC Kinetics Committee recommendations for collecting experimental thermal analysis data for kinetic computations. Thermochim. Acta 2014, 590, 1-23.

(47) Ramesh, R.; Spaldin, N. A. Multiferroics: progress and prospects in thin films. Nat. Mater. 2007, 6, 21-29. 
(48) Bibes, M.; Barthelemy, A. Multiferroics: Towards a magnetoelectric memory. Nat. Mater. 2008, 7, 425-426.

(49) Perejon, A.; Murafa, N.; Sanchez-Jimenez, P. E.; Criado, J. M.; Subrt, J.; Dianez, M. J.; Perez-Maqueda, L. A. Direct mechanosynthesis of pure $\mathrm{BiFeO}_{3}$ perovskite nanoparticles: reaction mechanism. J. Mater. Chem. C 2013, 1, 3551-3562.

(50) Young, R. A., The Rietveld method. (IUCr Monograph on Crystallography, $N^{o}$ 5), Internatonal Union of Crystallography/Oxford University Press, 1993.

(51) Le Bail, A. Whole powder pattern decomposition methods and applications: A retrospection. Powder Diffr. 2005, 20, 316-326.

(52) Bruker TOPAS 5 User Manual, 2014.

(53) Moreau, J. M.; Michel, C.; Gerson, R.; James, W. J. Ferroelectric BiFeO3 X-ray and neutron diffraction study. J. Phys. Chem. Solids 1971, 32, 1315-1320.

(54) Arnold, D. C.; Knight, K. S.; Morrison, F. D.; Lightfoot, P. FerroelectricParaelectric Transition in $\mathrm{BiFeO}_{3}$ : Crystal Structure of the Orthorhombic beta Phase. Phys. Rev. Lett. 2009, 102. 027602.

(55) Arnold, D. C. Composition-Driven Structural Phase Transitions in Rare-EarthDoped $\mathrm{BiFeO}_{3}$ Ceramics: A Review. IEEE Trans. Ultrason. Ferroelectr. Freq. Control 2015, 62, 62-82.

(56) Szafraniak, I.; Połomska, M.; Hilczer, B.; Pietraszko, A.; Kępiński, L. Characterization of $\mathrm{BiFeO}_{3}$ nanopowder obtained by mechanochemical synthesis. J. Eur. Ceram. Soc. 2007, 27, 4399-4402.

(57) Palai, R.; Katiyar, R.; Schmid, H.; Tissot, P.; Clark, S.; Robertson, J.; Redfern, S.; Catalan, G.; Scott, J. $\beta$ phase and $\gamma-\beta$ metal-insulator transition in multiferroic BiFeO3. Phys. Rev. B 2008, 77, 014110.

(58) Sánchez-Jiménez, P. E.; Perejón, A.; Pérez-Maqueda, L. A.; Criado, J. M. New Insights on the Kinetic Analysis of Isothermal Data: The Independence of the Activation Energy from the Assumed Kinetic Model. Energy Fuels 2015, 29, 392397.

(59) Vyazovkin, S.; Burnham, A. K.; Criado, J. M.; Perez-Maqueda, L. A.; Popescu, C.; Sbirrazzuoli, N. ICTAC Kinetics Committee recommendations for performing kinetic computations on thermal analysis data. Thermochim. Acta 2011, 520, 1-19.

(60) Friedman, H. L. Kinetics of thermal degradation of char-forming plastics from thermogravimetry. Application to phenolic plastic. J. Polym. Sci. Pol. Sym 1964, 6, 183-195. 
(61) Criado, J. M.; Sanchez-Jimenez, P. E.; Perez-Maqueda, L. A. Critical Study of the Isoconversional Methods of Kinetic Analysis. J. Therm. Anal. Calorim. 2008, 92, 199-203.

(62) Perez-Maqueda, L. A.; Sanchez-Jimenez, P. E.; Criado, J. M. Evaluation of the integral methods for the kinetic study of thermally stimulated processes in polymer science. Polymer 2005, 46, 2950-2954.

(63) Ortega, A.; Perez-Maqueda, L. A.; Criado, J. M. A new point of view on the evaluation of the temperature integral. Thermochim. Acta 1996, 283, 29-34.

(64) Pérez-Maqueda, L. A.; Criado, J. M.; Sánchez-Jiménez, P. E. Combined Kinetic Analysis of Solid-State Reactions: A Powerful Tool for the Simultaneous Determination of Kinetic Parameters and the Kinetic Model without Previous Assumptions on the Reaction Mechanism. J. Phys. Chem. A 2006, 110, 1245612462.

(65) Sanchez-Jimenez, P. E.; Perez-Maqueda, L. A.; Perejon, A.; Criado, J. M. Combined kinetic analysis of thermal degradation of polymeric materials under any thermal pathway. Polym. Degrad. Stabil. 2009, 94, 2079-2085.

(66) Pérez-Maqueda, L. A.; Criado, J. M.; Málek, J. Combined Kinetic Analysis for Crystallization Kinetics of Non-Crystalline Solids. J. Non-Cryst. Solids 2003, 320, 84-91.

(67) Johnson, W. A.; Mehl, R. F. Reaction kinetics in processes of nucleation and growth. Trans. Am. Inst. Min. Metall. Eng. 1939, 135, 416-442.

(68) Avrami, M. Kinetics of Phase Change. II Transformation-Time Relations for Random Distribution of Nuclei. J. Chem. Phys. 1940, 8, 212-224.

(69) Švadlák, D.; Shánělová, J.; Málek, J.; Pérez-Maqueda, L. A.; Criado, J. M.; Mitsuhashi, T. Nanocrystallization of anatase in amorphous $\mathrm{TiO}_{2}$. Thermochim. Acta 2004, 414, 137-143. 


\section{Crystallization kinetics of nanocrystalline materials by combined X-ray diffraction and differential scanning calorimetry experiments}

Eva Gil-González ${ }^{\mathrm{a}}$, Antonio Perejón a,b,*, Pedro E. Sánchez-Jiménez ${ }^{\mathrm{a}}$, Santiago Medina-Carrasco ${ }^{\mathrm{c}}$, Jaroslav Kupčík ${ }^{\mathrm{d}}$, Jan Šubrt ${ }^{\mathrm{d}}$, José Manuel Criado ${ }^{\mathrm{a}}$, Luis A. Pérez-Maqueda ${ }^{\mathrm{a}, *}$

${ }^{a}$ Instituto de Ciencia de Materiales de Sevilla (C.S.I.C.-Universidad de Sevilla). C. Américo Vespucio 49, Sevilla 41092. Spain

${ }^{b}$ Departamento de Quimica Inorgánica, Facultad de Química, Universidad de Sevilla, Sevilla 41071, Spain

${ }^{c} X$-Ray Laboratory (CITIUS), University of Seville, Avenida Reina Mercedes, 4B., 41012 Sevilla, Spain

${ }^{d}$ Institute of Inorganic Chemistry of the CAS, v.v.i., CZ-250 68 Husinec- $\check{R} e z ̌$, Czech Republic
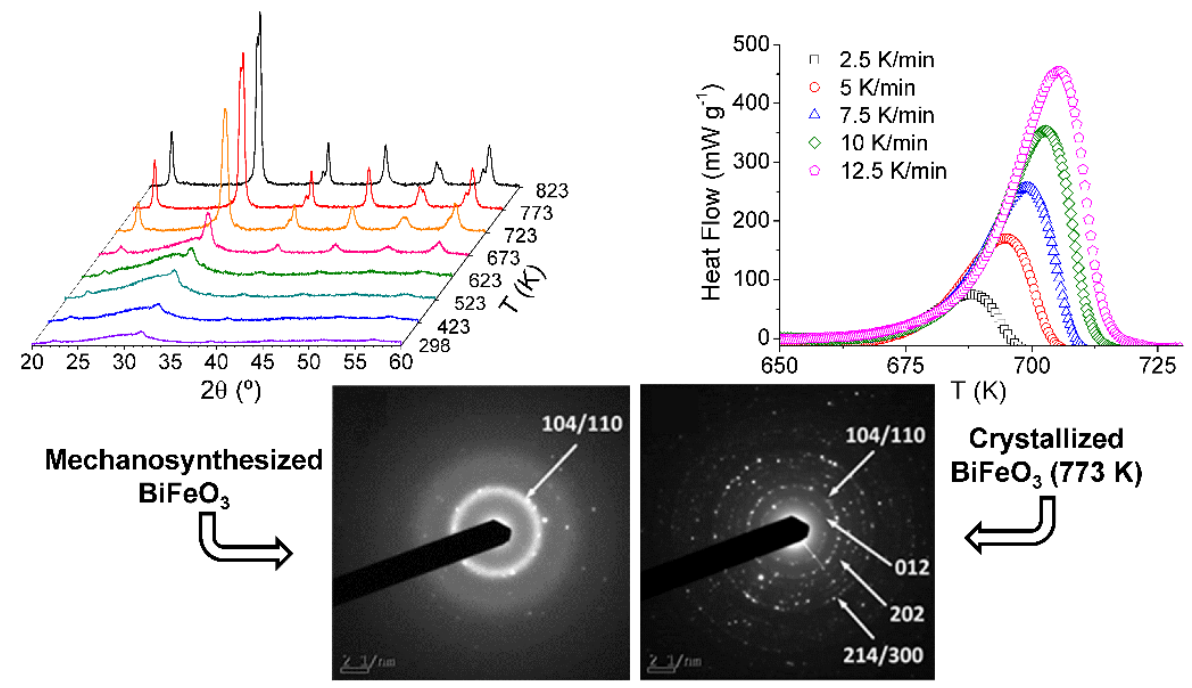

The thermal crystallization of nanocrystalline $\mathrm{BiFeO}_{3}$ has been studied by combining the information obtained from in situ high-temperature XRD, TEM and DSC. The kinetic analysis of the X-ray diffraction and DSC data yields almost identical results, which allows the unambiguous determination of the kinetic parameters. The importance of a proper definition of the conversion degree is also highlighted. 